co-design of local solutions to problems of healthcare accessibility and confidence in self management. Local CCG commissioners are now funding a wider local tour and we are working on next steps to broaden reach of the events.

\section{G322(P) THE DEVELOPMENT OF A PAEDIATRIC SHORT STAY UNIT}

RC Mitchell, L Watt, S Beadle, S Harris, M Bearsmore-Rust, O Akindolie. Department of Ambulatory Paediatrics, Kings College Hospital NHS Foundation Trust, London, UK

10.1136/archdischild-2015-308599.299

Aims There has been pioneering reshaping of our hospital's ambulatory paediatric services over the last year. In line with the RCPCH report 'Short Stay Paediatric Assessment Units', published in 2009, a paediatric short stay unit (PSSU) opened in July 2014, for children needing admission for less than 48 h. It is a consultant delivered service, which aims to meet and exceed the RCPCH 'Facing the Future' standards of care.

Methods Activity data for the first 5 months has been analysed and the impact upon other paediatric services assessed. Patient experience has also been evaluated.

Results To date, 466 patients have been admitted to PSSU with a median length of stay of $18 \mathrm{~h}$. Elsewhere in the trust, there have been fewer general paediatric bed days (1233) since PSSU opening, compared to 1548 for the same period last year. Since PSSU opening, only 1 patient has been 'treated and transferred' to another hospital from PED due to lack of capacity, compared to 10 for the same period last year. Patient satisfaction questionnaires have reported that $76 \%$ of families would recommend PSSU to friends and family if they needed similar care or treatment. The comments from patients and their families about PSSU have been overwhelmingly positive (Figure 1).

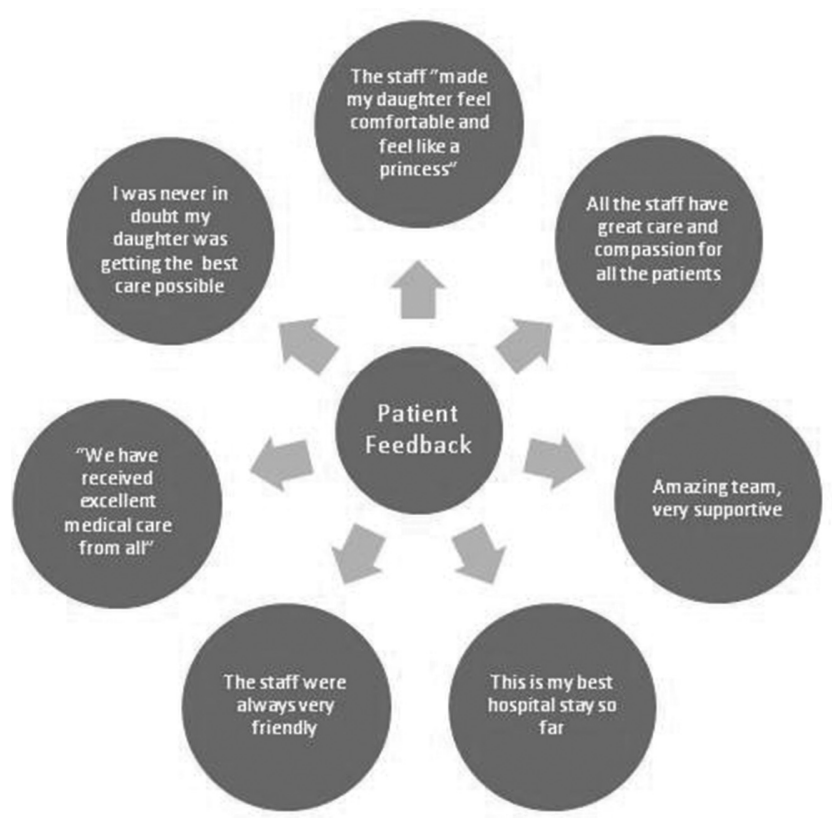

Abstract G322(P) Figure 1 Examples of patient feedback collected in September 2014
Conclusion PSSU has been phenomenally successful in streamlining the patient journey for children requiring hospital admission for less than $48 \mathrm{~h}$. There have been significant secondary gains elsewhere, with reduced numbers of patients needing transfer to other hospitals from PED due to lack of capacity, and increased numbers of inpatient beds for speciality patients. The model of a paediatric short stay unit is here to stay; as was highlighted by 'Facing the Future' publication, acute paediatric care should be delivered in a specialised setting, fronted by senior staff who truly believe in the service. This PSSU is one example of this, as a successful expansion of our ambulatory paediatrics service.

\section{G323(P) TRANSCUTANEOUS BILIRUBIN MEASUREMENT IN NEONATES WITH JAUNDICE REQUIRING PHOTOTHERAPY}

BG Fisher, R Lakshman. Department of Paediatrics, West Suffolk NHS Foundation Trust, Bury St Edmunds, UK

\subsection{6/archdischild-2015-308599.300}

Background UK guidelines advocate the use of transcutaneous bilirubin (TCBR) estimation in neonates with jaundice aged $>24$ $\mathrm{h}$ with a gestational age of $\geq 35$ weeks, but not in neonates who have had phototherapy, as there is a more rapid fall in dermal vs. serum bilirubin with phototherapy. A recent study demonstrated that whilst TCBR underestimated SBR within the first 8 $\mathrm{h}$ after phototherapy, its accuracy returned to pre-treatment values after $24 \mathrm{~h}$. This suggests a possible role for TCBR monitoring in infants who have had phototherapy $>24 \mathrm{~h}$ ago, reducing the number of both blood tests and hospital visits.

Aim To compare TBCR and SBR measurements before, during and after phototherapy in neonates.

Methods This was a prospective observational study at a UK district general hospital. Participants were all neonates admitted to the neonatal unit or postnatal ward who required an SBR measurement for jaundice monitoring as per UK guidelines. TBCR measurement was performed using a Dräger Jaundice Metre JM-103 within $10 \mathrm{~min}$ of the SBR sampling. SBR was determined by blood gas analysis. Safety margins (mean difference $-2.33 \times \mathrm{SD}-50$ ) were calculated for TCBR readings during phototherapy to correctly assign $99 \%$ of neonates to stop receiving phototherapy, i.e. SBR $>50 \mu \mathrm{mol} / \mathrm{l}$ below the treatment threshold.

Results Pilot data: 8 neonates (gestation $34+4$ to $42+0,4$ male) had a total of 11 simultaneous measurements. Measuring TCBR on the forehead, the mean (SD) difference (TCBR - SBR) before phototherapy was $-45 \mu \mathrm{mol} / \mathrm{l}(17 \mu \mathrm{mol} / \mathrm{l})$, during phototherapy was $-102 \mu \mathrm{mol} / \mathrm{l}(8 \mu \mathrm{mol} / \mathrm{l})$, and at $>16 \mathrm{~h}$ after phototherapy was $-48 \mu \mathrm{mol} / \mathrm{l} \quad(6 \mu \mathrm{mol} / \mathrm{l})$. Values were similar measuring TCBR on the sternum. During phototherapy, TCBR levels of $-171 \mu \mathrm{mol} / \mathrm{l}$ below the treatment threshold allowed safe cessation of phototherapy without confirmatory SBR testing.

Conclusion TCBR measurements $>16 \mathrm{~h}$ after phototherapy appear to be equally as accurate as before phototherapy, which could obviate the need for SBR measurement when checking for a rebound rise in bilirubin after stopping phototherapy. More comprehensive data will be collected in time for presentation at the RCPCH Conference. 


\section{G324(P) ABSTRACT WITHDRAWN}

\section{G325(P) TO ERR IS HUMAN: THEMATIC CHARACTERISATION OF PAEDIATRIC CLINICAL INCIDENTS WITHIN A LARGE DISTRICT GENERAL HOSPITAL}

S Li, H Sadreddini, J Surridge. Derby Children's Hospital, Royal Derby Hospital, Derby, UK

10.1136/archdischild-2015-308599.301

Aims Our children's hospital encompasses several acute clinical areas. These include paediatric medical and surgical inpatient wards (including the children's high dependency ward), the children's emergency department and the neonatal intensive care unit. Collectively these are busy and challenging environments where the provision of care is increasingly complex. These provide opportunities for errors to occur making unintended consequences to harm more likely. The Francis report published in February 2013 highlighted the need for openness and transparency in regards to patient safety. We reviewed clinical incidents reported within all acute clinical paediatric areas in order to characterise commonly recurring themes.

Method Clinical incident forms from all acute paediatric clinical areas from 1 September 2012 until 31 August 2014 were retrospectively reviewed. Incidents were assessed for the degree of actual harm caused to patients. They were subsequently categorised according to the National Reporting and Learning System incident types for each clinical area. Medications incidents were further sub-classified by type.

Results 872 incident forms involving all acute paediatric clinical areas were submitted over a 24 month period. $67 \%$ of all clinical incidents were reported as having insignificant harm to patients and only $2 \%$ as catastrophic. The types of incidents reported are shown in Figure 1. Medication errors accounted for a significant percentage of reported incidents within each clinical area (19\% children's emergency department; 30\% children's wards; $26 \%$ neonatal intensive care unit). Other commonly reported incidents were infrastructure problems and patient

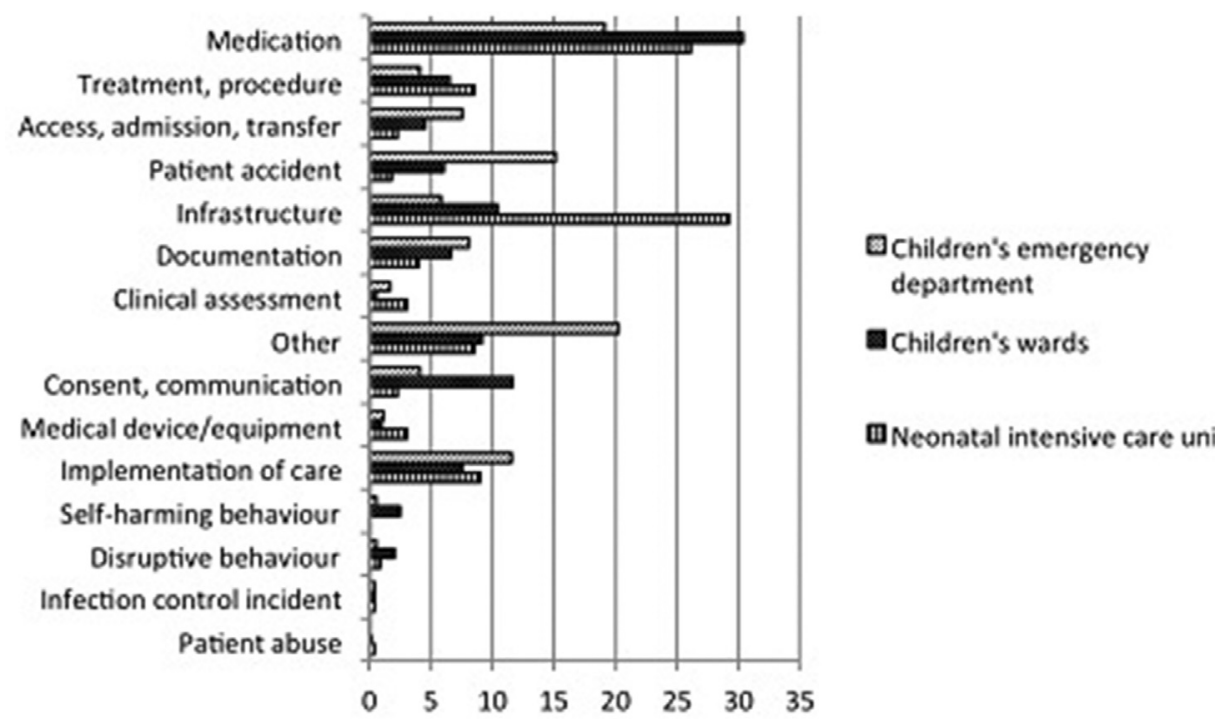

Abstract G325(P) Figure 1 Percentage of reported incident types

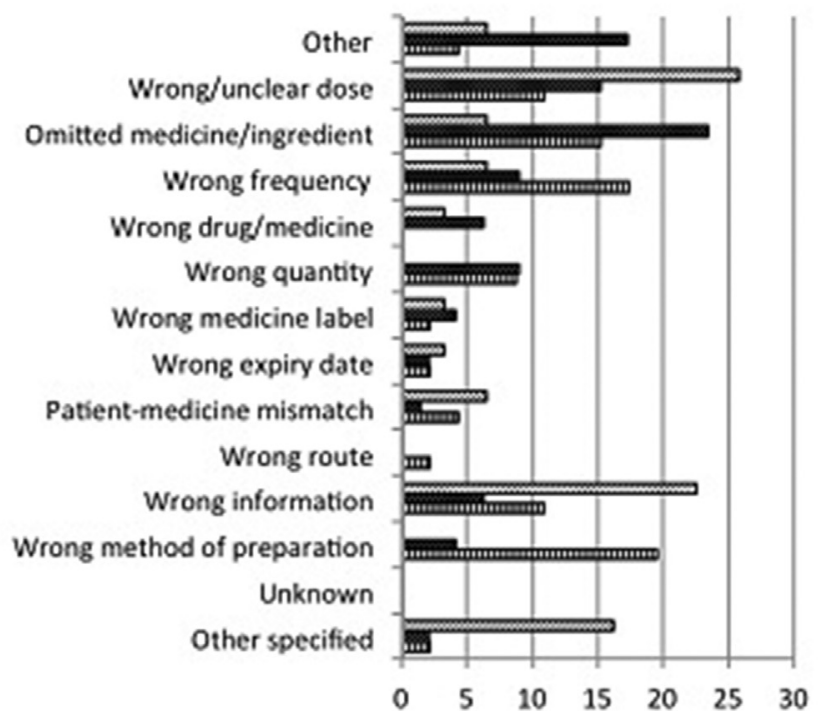

\section{DChildren's emergency department}

Children's wards

四eonatal intensive care un

Abstract G325(P) Figure 2 Percentage of medication incidents by specified types 